\title{
A Universal Simulation Method to Calculate Power Losses of IGBTs and Anti-Parallel Diodes
}

\author{
En Fang *, Xiaojie Wu, Yuesen Yu and Junting Liu \\ School of Information and Electrical Engineering, China University of Mining \\ and Technology, Xuzhou 221008, Jiangsu Province, China \\ *Corresponding Author: En Fang, 15862152007@163.com
}

\begin{abstract}
In this paper, a universal loss calculation model in simulation is established in MATLAB / Simulink which can be used in not only ideal but also non-ideal conditions ( non-sinusoidal load current and grid voltage, unfixed system parameters such as stator resistance for induction motors, unstable DC voltage with fluctuation, aperiodic modulation strategies with unfixed switching frequency, and so on). Considering the influence of dead time, steady operating states of each device can be obtained by the measurement of the load current and gate triggering pulses of every IGBT in a phase arm which can be easily measured in experiment rather than the currents and voltages of devices. Analyses in two-level topology and Neutral-Point-Clamped (NPC) three-level topology were done as examples. In periodic pulse width modulation with sinusoidal modulation wave, consistency among results from the proposed simulation model, the formula commonly used and commercially available loss software provided by power device manufacturer was shown. Through the design of a two-level inverter in hysteretic control, experimental verification of proposed method was applied. Calculating power loss in this method can be adapted to different converter topologies with various control strategies which is not even for ideal conditions.
\end{abstract}

Keywords: losses in IGBTs and anti-parallel diodes, loss calculation, converter loss, unfixed frequency

\section{Nomenclature}

A Quadratic coefficient for quadratic polynomial fitting of switching loss and current according to the least-square method $\left[\mathrm{mJ} / \mathrm{A}^{2}\right]$

$B$ Monomial coefficient for quadratic polynomial fitting of switching loss and current according to the least-square method [mJ/A]

$C$ Constant term for quadratic polynomial fitting of switching loss and current according to the least-square method $[\mathrm{mJ}]$

$E$ Power loss [W]

$f \quad$ Frequency $[\mathrm{Hz}]$

$i(t)$ Real-time current through the device [A]

I Current amplitude [A]

$K$ Correction coefficient for junction temperature relative to the base junction temperature

$M$ Modulation ratio

$r$ Conduction resistance $[\Omega]$

$R \quad$ Conduction resistance at the base junction temperature

$t \quad$ Time[s]

$T$ Temperature $\left[{ }^{\circ} \mathrm{C}\right]$

$u(t)$ Real-time voltage of device [V]

$U \quad$ Voltage amplitude [V] 
$\varphi \quad$ The phase difference of voltage and current [rad]

\section{Subscripts}

2 For saturation voltage in conduction

3 For conduction resistance

avg Average value

base Base parameters for switching loss curve

ce Between collector and emitter

con In conduction process

Diode For device of diode

IGBT For device of IGBT

$\mathrm{j}$ At junction

on In turn-on process

off In turn-off process

rec In reverse recovery process

sat Saturation parameters in conduction

sw In switching process

\section{Introduction}

In recent years, with rapid development of high voltage and high power converters which results in appearance of new topologies [1, 2] and control strategies one after another, high working temperature due to high power consumption of power devices has been one of the restricting factors. In the design of high power converters, thermal management with power loss calculation to determine the method of cooling and identify thermal resistance distribution throughout various parts of the thermal path gets tremendous impact on device performance. The sizing and materials of heat sinks, in addition to the choice of cooling methods, the selection of fans or pumps and arrangement in converters, etc., are dictated by the losses which affect the converter reliability and life. Due to characteristics of devices, the power across the device is not maintained zero which results in power loss during operation. The loss transfers to environment through heat sink as heat, and thereby affects the operation as junction temperature of the devices. The negative influence of high power dissipation on junction temperature is often brought resulting in degradation of device performance and the efficiency decrease. Loss calculation methods currently used are mostly based on two-level topology and ideal conditions (perfect sinusoidal load current and grid voltage, fixed system parameters, stable DC voltage without fluctuation, periodic modulation strategies with fixed switching frequency, and so on). There are only a few studies about loss calculation on the multi-level topologies or aperiodic control strategies.

Currently, for high voltage and high power applications, different multi-level converter topologies have been proposed to settle the low withstand voltage problem of power devices [3], considering aspects of electrical performance, system efficiency, size and cost, and so on. These topologies are mainly divided into two types: cascaded multi-level and clamped multi-level, and IGBTs are often adopted as power devices. Numerous studies were carried out on electrical performance of multi-level topologies. It is confirmed that multi-level converter topologies show great electrical properties and applicability in different areas of high voltage and high power occasions [4-6]. And different control strategies in these topologies have been raised for different control objects and targets [7]. Multi-level converter products appear in market as the control strategies are implemented. However, the development and industrialization of multi-level 
converter products are restricted due to few studies on power loss calculation in multi-level topologies [8].

According to aperiodic variation of working conditions and other factors, such as stator and rotor parameters of induction motors changing with temperature, grid voltage fluctuation and device characteristics change, the working status may not change periodically. In order to obtain better control effect, the feedback of these parameter changes should be introduced into the control strategy so that the control parameters and program can be adjusted with real-time control results. But the original methods could only be applied to calculate the power loss under ideal conditions without these parameter changes; on the other hand, in recent years, predictive control strategy, genetic algorithms, expert control systems and other intelligent control strategies have been greatly developed, but the differences between results of the original power loss calculation methods for such control strategies with non-constant switching frequency and actual results are often remarkable[9]. For high voltage and high power converters, these errors may lead to enormous economic loss.

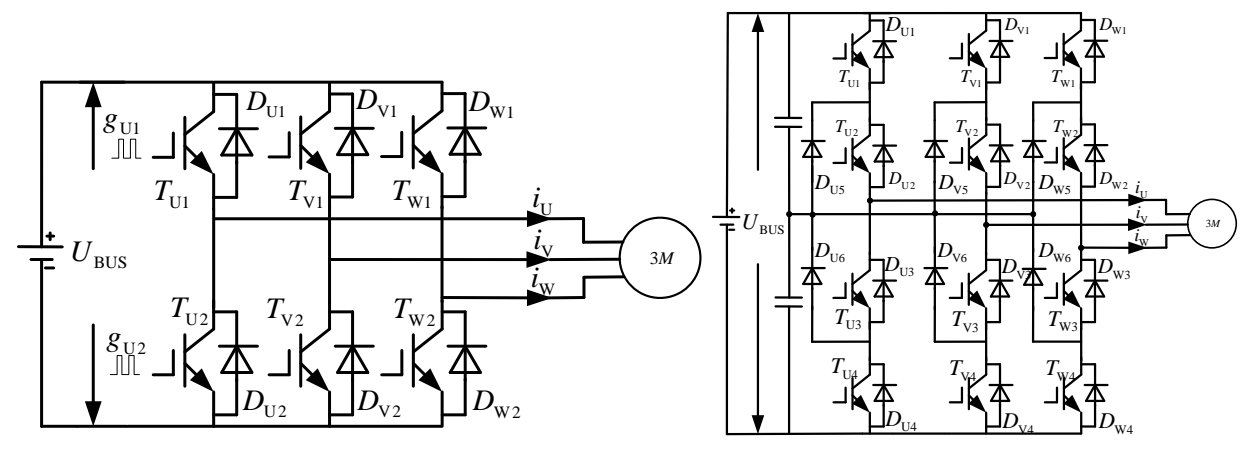

(a) Two-level topology

(b) Neutral-Point-Clamped three-level topology

Figure 1. Typical Voltage Source Inverter Power Circuit

\section{Modeling for Loss Calculation of IGBTs and Anti-Parallel Diodes}

In a motor control application, the typical switching waveforms of the voltage and current in IGBTs or anti-parallel diodes are shown in Figure 2.

During operation at moderate temperatures, the leakage current of IGBT or antiparallel diode is so small that the off-state loss can be ignored. Included the turn-on switching loss, turn-off switching loss and conduction loss, power losses of the device are associated with its own physical structure, characteristics of the production process and working conditions. Because fast recovery diodes are generally used as anti-parallel diode, turn-on loss of anti-parallel diodes with respect to turn-off loss and conduction loss is negligible. 


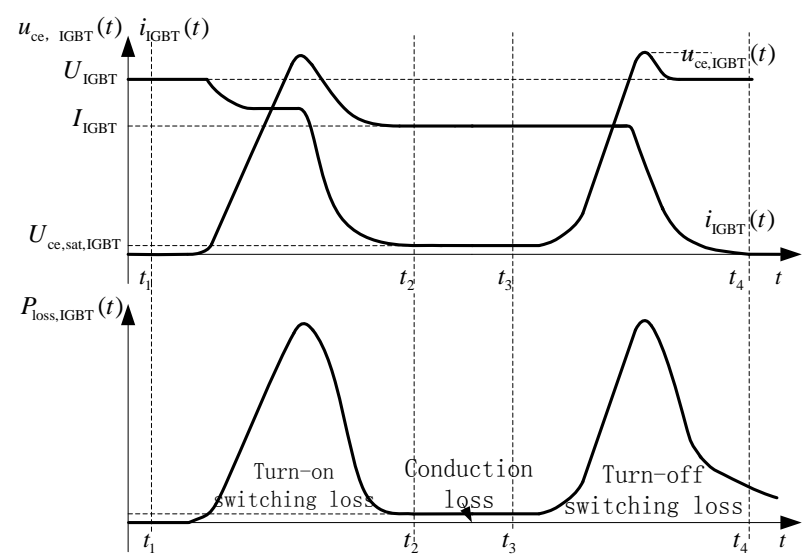

Figure 2. Typical Switching Waveforms of the Voltage and Current in IGBT and Anti-Parallel Diodes [10]

\subsection{Turn-on switching loss and turn-off switching loss.}

The power devices in the circuit play a major role as switches to control the circuit on and off. A large number of high-order harmonic components may be introduced due to device switching. In general, better electrical performance can be reached under higher switching frequency within a certain range with greater switching loss. The corresponding thermal management cost would be higher in order to keep the device working under the maximum operating junction temperature. Therefore, the switching frequency is often performed as a compromise selection between electrical performance and thermal management. In order to reduce the switching loss, there are a lot of researches for reaching an effect of higher equivalent switching frequency at a low device switching frequency.

In two-level topology, the turn-on loss of IGBT is mainly determined by the reverse recovery characteristics of free-wheeling diode (usually the free-wheeling diode is consistent with the anti-parallel diode) [11]. On the contrary, the turn-off loss is determined by the turn-off characteristics of IGBT [12]. According to the definition, the effects of switching waveforms and device characteristics, the switching loss curves of current provides convenient expressions for switching loss calculation of devices in a switching cycle by quadratic polynomial fitting:

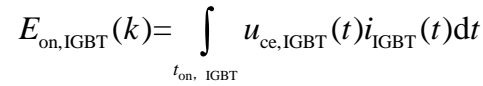

$$
\begin{aligned}
& =\left[A_{\text {on,IGBT }} i_{\text {IGBT }}^{2}(k)+B_{\text {on,IGBT IGBT }} i_{\text {IGB }}(k)+C_{\text {on,IGBT }}(k)\right]\left[\frac{U_{\text {ce,IGBT }}(k)}{U_{\text {base,IGBT }}}\right]\left[\frac{T_{\mathrm{j}, \mathrm{IGBT}}(k)}{T_{\text {base,IGBT }}}\right]^{K_{\text {on,IGBT }}} \\
& E_{\text {off,IGBT }}(k)=\int_{t_{\text {off, IGBT }}} u_{\text {ce,IGBT }}(t) i_{\mathrm{IGBT}}(t) \mathrm{d} t
\end{aligned}
$$

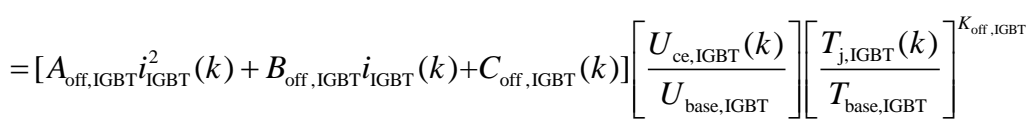

$$
\begin{aligned}
& E_{\text {on,Diode }}(k)=0 \\
& E_{\text {rec,Diode }}(k)=\int_{t_{\text {rec,Diode }}} u_{\text {Diode }}(t) i_{\text {Diode }}(t) \mathrm{d} t \\
& =\left[A_{\text {rec, Diode }} i_{\text {Diode }}^{2}(k)+B_{\text {rec,Diode }} i_{\text {Diode }}(k)+C_{\text {rec,Diode }}(k)\right]\left[\frac{U_{\text {Diode }}(k)}{U_{\text {Diode }}}\right]\left[\frac{T_{\text {,Diode }}(k)}{T_{\text {base,Diode }}}\right]^{K_{\text {rex, Diode }}}
\end{aligned}
$$


Average switching power loss of the device during switching time can be calculated as follows:

\subsection{Conduction Loss}

$$
\begin{gathered}
P_{\mathrm{on}, \mathrm{IGBT}, \mathrm{avg}}(k)=\frac{E_{\mathrm{on}, \mathrm{IGBT}}(k)}{t_{\mathrm{on}, \mathrm{IGBT}}} \\
P_{\mathrm{off}, \mathrm{IGBT}, \text { avg }}(k)=\frac{E_{\mathrm{off}, \mathrm{IGBT}}(k)}{t_{\mathrm{off}, \mathrm{IGBT}}} \\
P_{\text {rec,Diode,avg }}(k)=\frac{E_{\text {rec,Diode }}(k)}{t_{\text {rec,Diode }}}
\end{gathered}
$$

Associated to conduction saturation voltage drop $u_{\text {ce,sat }}(t)$, the real-time current $i(t)$, the junction temperature $T_{j}$ and conduction time $t_{\text {con }}$, the conduction loss of the device can be obtained as follows:

$$
\begin{aligned}
& P_{\text {con,IGBT }}=u_{\text {ce,IGBT }}(t) i_{\mathrm{IGBT}}(t) \\
& =\left[u_{\mathrm{ce}, \mathrm{sa}, \mathrm{IGBT}}+r_{\mathrm{IGBT}} i_{\mathrm{IGBT}}(k)\right] i_{\mathrm{IGBT}}(k) \\
& =\left[U_{\text {ce,sat,IGBT }}+K_{u_{\text {ce, sat,IGBT }}}\left(T_{\mathrm{j}, \mathrm{IGBT}}-T_{\text {base2,IGBT }}\right)\right] i_{\mathrm{IGBT}}(k) \\
& +\left[R_{\mathrm{IGBT}}+K_{r_{\text {satl.IGT }}}\left(T_{\mathrm{j}, \mathrm{IGBT}}-T_{\text {base3,IGBT }}\right)\right] i_{\mathrm{IGBT}}^{2}(k) \\
& E_{\text {con, Diode }}=\int_{t_{\text {con,Diode }}} u_{\text {Diode }}(t) i_{\text {Diode }}(t) \mathrm{d} t=\int_{t_{\text {con, Diode }}}\left[u_{\text {sat, Diode }}+r_{\text {Diode }} i_{\text {Diode }}(t)\right] i_{\text {Diode }}(t) \mathrm{d} t \\
& =\int_{t_{\text {con, Diode }}}\left\{\begin{array}{l}
{\left[U_{\text {sat,Diode }}+K_{u_{\text {sat,Diode }}}\left(T_{\mathrm{j}, \text { Diode }}-T_{\text {base2,Diode }}\right)\right]} \\
+\left[R_{\text {Diode }}+K_{r_{\text {sat,Diode }}}\left(T_{\mathrm{j}, \text { Diode }}-T_{\text {base3,Diode }}\right)\right] i_{\text {Diode }}(t)
\end{array}\right\} i_{\text {Diode }}(t) \mathrm{d} t
\end{aligned}
$$

\section{Power Loss Calculation Method by Simulation}

The characteristic and working state parameters in process of switching, blocking and conduction play a significant role in thermal management for power loss calculation of specific IGBT or anti-parallel diode [14]. The loss mechanism has been analyzed based on two-level topology or NPC three-level topology for periodic ideal sinusoidal pulse width modulation strategy [15]. And the corresponding calculation formulas of power loss were obtained. However, on one hand, as there are a large number of redundant switching states, the working state parameters are unable to get through this way in multi-level converters. On the other hand, there have been only a few studies on power loss calculation under nonideal or aperiodic control strategy due to unfixed switching frequency $[9,16]$. For a specific topology the power loss of device can be obtained by analyzing the following parameters conveniently obtained by simulation or experiments: blocking voltage of the device, load current, and gate triggering pulses of every IGBT (it is based on MATLAB / Simulink simulation platform in this paper).

As shown in Figure 1(a), taking phase arm $U$ in two-level converter as an example, power devices of IGBTs or anti-parallel diodes are labeled as $T_{\mathrm{U} x}$ and $D_{\mathrm{U} x},(x=1,2.1$ stands for upper one; 2 stands for lower one), and the corresponding gate triggering signal of IGBT is $g_{\mathrm{U} x}$. If $g_{\mathrm{U} x}=1$, the gate triggering signal is positive; if $g_{U x}=0$, the gate signal is negative. For certain systems, the gate voltage, the gate turn-on and turn-off resistors are generally fixed. The influence of these factors on the loss calculation should have been taken into account as a correction coefficient in the mathematical models. Therefore, considering the dead-time, there 
are three cases of gate triggering signals in a phase arm. Load current $i_{\mathrm{U}}$ is specified to be positive if it flows out of the phase arm $U$ pointing towards the load. Thus, according to the load current and every IGBT gate triggering signal, working states of the devices can be obtained as shown in Table 1.

Table 1. Working States of the Devices in Two-Level Topology

\begin{tabular}{ccccccc}
\hline $\begin{array}{c}\text { Load } \\
\text { current }\end{array}$ & $\begin{array}{c}\text { Gate triggering } \\
\text { signal of upper } \\
\text { IGBT }\end{array}$ & $\begin{array}{c}\text { Gate triggering } \\
\text { signal of lower } \\
\text { IGBT }\end{array}$ & \multicolumn{4}{c}{ Working state of the devices } \\
\hline \multirow{4}{*}{$i_{\mathrm{U}}>0$} & $g_{\mathrm{U} 1}=0$ & $g_{\mathrm{U} 2}=0$ & OFF & OFF & OFF & ON \\
& $g_{\mathrm{U} 1}=1$ & $g_{\mathrm{U} 2}=0$ & ON & OFF & OFF & OFF \\
& $g_{\mathrm{U} 1}=0$ & $g_{\mathrm{U} 2}=1$ & OFF & OFF & OFF & ON \\
& $g_{\mathrm{U} 1}=0$ & $g_{\mathrm{U} 2}=0$ & OFF & OFF & ON & OFF \\
& $g_{\mathrm{U} 1}=1$ & $g_{\mathrm{U} 2}=0$ & OFF & OFF & ON & OFF \\
$i_{\mathrm{U}} \leq 0$ & $g_{\mathrm{U} 1}=0$ & $g_{\mathrm{U} 2}=1$ & OFF & ON & OFF & OFF \\
\hline
\end{tabular}

In the same way, the working states of the devices labeled as shown in Figure 1(b) in NPC three-level topology would be obtained as shown in Table 2.

Table 2. Working States Of The Devices In Npc Three-Level Topology

\begin{tabular}{|c|c|c|c|c|c|c|c|c|c|c|c|c|c|c|}
\hline \multirow{3}{*}{$\begin{array}{c}\text { Load } \\
\text { current }\end{array}$} & \multirow{2}{*}{\multicolumn{4}{|c|}{ Gate triggering signals }} & \multicolumn{10}{|c|}{ Working states of the devices } \\
\hline & & & & & $\mathrm{T}_{\mathrm{U} 1}$ & $\mathrm{~T}_{\mathrm{U} 2}$ & $\mathrm{D}_{\mathrm{U} 1}$ & $\mathrm{D}_{\mathrm{U} 2}$ & $\mathrm{~T}_{\mathrm{U} 3}$ & $\mathrm{~T}_{\mathrm{U} 4}$ & $\mathrm{D}_{\mathrm{U} 3}$ & $\mathrm{D}_{\mathrm{U} 4}$ & Dus & $\mathrm{D}_{\mathrm{U} 6}$ \\
\hline & $g_{\mathrm{U} 1}=1$ & $g_{\mathrm{U} 2}=1$ & $g_{\mathrm{U} 3}=0$ & $g_{\mathrm{U} 4}=0$ & ON & ON & OFF & OFF & OFF & OFF & OFF & OFF & OFF & OFF \\
\hline \multirow{6}{*}{$\begin{array}{c}i_{\mathrm{U}}> \\
0\end{array}$} & $g_{\mathrm{U} 1}=0$ & $g_{\mathrm{U} 2}=1$ & $g_{\mathrm{U} 3}=0$ & $g_{\mathrm{U} 4}=0$ & OFF & ON & OFF & OFF & OFF & OFF & OFF & OFF & ON & OFF \\
\hline & $g_{\mathrm{U} 1}=0$ & $g_{\mathrm{U} 2}=1$ & $g_{\mathrm{U} 3}=1$ & $g_{\mathrm{U} 4}=0$ & OFF & & OFF & OFF & OFF & OFF & OFF & OFF & ON & $\mathrm{OFF}$ \\
\hline & $g_{\mathrm{U} 1}=0$ & $g_{\mathrm{U} 2}=0$ & $g_{\mathrm{U} 3}=1$ & $g_{\mathrm{U} 4}=0$ & OFF & OFF & OFF & OFF & OFF & OFF & ON & ON & OFF & OFF \\
\hline & $g_{\mathrm{U} 1}=0$ & $g_{\mathrm{U} 2}=0$ & $g_{\mathrm{U} 3}=1$ & $g_{\mathrm{U} 4}=1$ & OFF & OFF & OFF & OFF & OFF & OFF & ON & ON & OFF & OFF \\
\hline & $g_{\mathrm{U} 1}=1$ & $g_{\mathrm{U} 2}=1$ & $g_{\mathrm{U} 3}=0$ & $g_{\mathrm{U} 4}=0$ & OFF & OFF & $\mathrm{ON}$ & ON & OFF & OFF & OFF & OFF & OFF & OFF \\
\hline & $g_{\mathrm{U} 1}=0$ & $g_{\mathrm{U} 2}=1$ & $g_{\mathrm{U} 3}=0$ & $g_{\mathrm{U} 4}=0$ & OFF & OFF & ON & ON & OFF & OFF & OFF & OFF & OFF & OFF \\
\hline \multirow{3}{*}{$i_{\mathrm{U}} \leq 0$} & $g_{\mathrm{U} 1}=0$ & $g_{\mathrm{U} 2}=1$ & $g_{\mathrm{U} 3}=1$ & $g_{\mathrm{U} 4}=0$ & O11 & OFF & OFF & OFF & ON & OFF & OFF & OFF & OFF & ON \\
\hline & $g_{\mathrm{U} 1}=0$ & $g_{\mathrm{U} 2}=0$ & $g_{\mathrm{U} 3}=1$ & $g_{\mathrm{U} 4}=0$ & OFF & OFF & OFF & OFF & ON & OFF & OFF & OFF & OFF & ON \\
\hline & $g_{\mathrm{U} 1}=0$ & $g_{\mathrm{U} 2}=0$ & $g_{\mathrm{U} 3}=1$ & $g_{\mathrm{U} 4}=1$ & OFF & OFF & OFF & OFF & ON & ON & OFF & OFF & OFF & OFF \\
\hline
\end{tabular}

Combined with the previous working state, the behavior of the device is determined. The corresponding loss calculation will be done by formula as previously described, which can be integrated over time to obtain the average power loss in the corresponding period. The behavior judgment process is shown in Figure 3. 


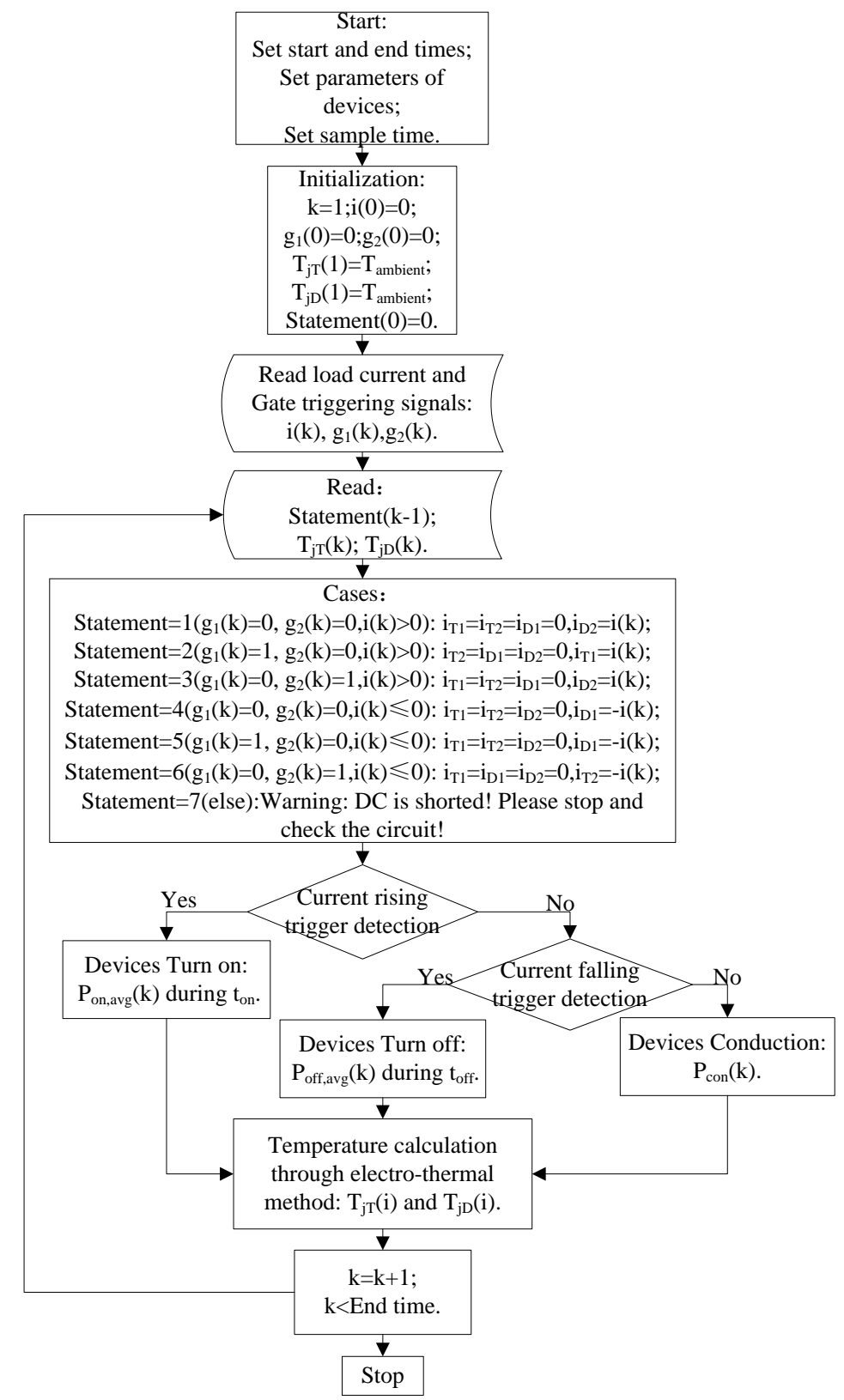

\section{Figure 3. Behavior Judgment Process in Two-Level Topology}

In simulation calculation model, the start and end times can be set during which the system is working in steady or transient state. And corresponding average power loss in this period will be recorded. It is beneficial for loss calculation and analysis in starting process, load mutation and other special working conditions. The knowledge of device properties of complicated physical structure is not required for IGBT [17] or anti-parallel diode model in this method and the switching frequency range can be observed by simulation due to unfixed switching period of gate triggering signals for non-ideal conditions or aperiodic control strategies. 


\section{Existing Loss Calculation Methods}

In two-level converters, the expression of $\mathrm{AC}$ voltage and current in time domains with sinusoidal periodic bipolar SPWM modulation is written as:

$$
\begin{gathered}
i(t)=I \sin (\omega t) \\
u(t)=U \sin (\omega t+\varphi)
\end{gathered}
$$

The duty radio is given by:

$$
\tau(t)=\frac{1+M \sin (\omega t+\varphi)}{2}
$$

By theoretical derivation, the power losses of IGBTs and anti-parallel diodes can be described by the expressions:

$$
\begin{aligned}
P_{\mathrm{con}, \mathrm{IGBT}}= & \left(\frac{1}{2 \pi}+\frac{M \cos \varphi}{8}\right) u_{\mathrm{cesat}, \mathrm{IGBT}} I \\
& +\left(\frac{1}{8}+\frac{M \cos \varphi}{3 \pi}\right) r_{\mathrm{IGBT}} I^{2} \\
P_{\mathrm{con}, \text { Diode }}= & \left(\frac{1}{2 \pi}-\frac{M \cos \varphi}{8}\right) u_{\mathrm{sat}, \text { Diode }} I \\
+ & \left(\frac{1}{8}-\frac{M \cos \varphi}{3 \pi}\right) r_{\text {Diode }} I^{2} \\
P_{\mathrm{sw}, \mathrm{IGBT}} & =E_{\mathrm{sw}, \mathrm{IGBT}} / t_{\mathrm{sw}}=f_{\mathrm{sw}} E_{\mathrm{sw}, \mathrm{IGBT}} \\
= & f_{\mathrm{sw}}\left(E_{\mathrm{on}, \mathrm{IGBT}}+E_{\mathrm{off}, \mathrm{IGBT}}\right) \\
P_{\mathrm{sw}, \text { Diode }} & =E_{\mathrm{sw}, \text { Diode }} / t_{\mathrm{sw}}=f_{\mathrm{sw}} E_{\mathrm{sw}, \text { Diode }} \\
& =f_{\mathrm{sw}}\left(E_{\mathrm{on}, \text { Diode }}+E_{\mathrm{off}, \text { Diode }}\right)
\end{aligned}
$$

This loss calculation method by formulas has been widely used. The loss calculation formulas for SVPWM control strategy and the NPC three-level converters have been given through a similar process.

In addition, power device manufacturers also introduced the corresponding commercial software for loss calculation in converters, such as IPOSIM of Infineon, IGBTSim of Fuji, MELCOSIM of MITSUBISHI, and so on. Detailed test data of device were integrated within the software so that the calculation should be more accurate. The junction temperature and thermal resistance were also considered. But the principle of the calculation was still based on periodic sinusoidal pulse width modulation strategy and software updates was far lagging behind in technological development. Those pieces of software showed poor portability for the introduction of new topologies and new control strategies in loss calculation.

\section{Verification of the Loss Calculation Method Comparing with Existing Methods}

A typical two-level converter simulation model was built with periodic ideal sinusoidal bipolar SPWM modulation $(\cos \varphi=0.8)$. Model FF200R33KF2C of Infineon was used as power devices. Parameters of IGBT and anti-parallel diode for calculation are listed in Table 3. The required parameters related to the device characteristics can be achieved by a typical double-pulse experiment [13] or quadratic polynomial fitting for curves provided by manufacturers according to the least-square method. In this paper, MATLAB was used for quadratic polynomial fitting the data of device characteristic curves obtained by data extraction software 
Getdata Dragh Digitizer. And then the parameters required for the calculation were achieved. It is more simple and versatile than experiment. For a specific device, compared the data obtained in this way with the experimentally measured data by manufacturer, there is a high degree of accuracy. The working state parameters such as load current and gate triggering pulses would be obtained by simulation. The junction temperatures of devices were obtained by electro-thermal circuit model [18].

Table 3. Parameters of Igbt and Anti-Parallel Diode [19][20]

\begin{tabular}{|c|c|c|}
\hline & IGBT & Anti-parallel diode \\
\hline $\begin{array}{l}\text { Coefficients in fitting equation of IGBT turn-on loss } \\
\text { and current based on quadratic polynomial fitting } \\
\text { according to the theory of the least-square method at } \\
\text { the base junction temperature with base blocking } \\
\text { voltage }\end{array}$ & $\begin{array}{c}A_{\mathrm{on}, \mathrm{IGBT}}=0.0047 \mathrm{~mJ} / \mathrm{A}^{2} \\
B_{\mathrm{on}, \mathrm{IGBT}}=0.5761 \mathrm{~mJ} / \mathrm{A} \\
C_{\mathrm{on}, \mathrm{IGBT}}=65.246 \mathrm{~mJ}\end{array}$ & \\
\hline $\begin{array}{c}\text { Coefficients in fitting equation of IGBT turn-off loss } \\
\text { and current based on quadratic polynomial fitting } \\
\text { according to the theory of the least-square method at } \\
\text { the base junction temperature with base blocking } \\
\text { voltage }\end{array}$ & $\begin{array}{c}A_{\text {off, IGBT }}=- \\
0.00008 \mathrm{~mJ} / \mathrm{A}^{2} \\
B_{\text {off,IGBT }}=1.1594 \mathrm{~mJ} / \mathrm{A} \\
C_{\text {off,IGBT }}=27.098 \mathrm{~mJ}\end{array}$ & $\begin{aligned} A_{\text {rec,Diode }} & =-0.0015 \mathrm{~mJ} / \mathrm{A}^{2} \\
B_{\text {rec,Diode }} & =1.1917 \mathrm{~mJ} / \mathrm{A} \\
C_{\text {rec,Diode }} & =79.808 \mathrm{~mJ}\end{aligned}$ \\
\hline Base blocking voltage & $U_{\text {base,IGBT }}=1800 \mathrm{~V}$ & $U_{\text {base,Diode }}=1800 \mathrm{~V}$ \\
\hline Base junction temperature & $\begin{array}{c}T_{\text {base,IGBT }}=T_{\text {base2,IGBT }}= \\
T_{\text {base3,IGBT }}=125^{\circ} \mathrm{C}\end{array}$ & $\begin{array}{c}T_{\text {base,Diode }}=T_{\text {base2,Diode }}= \\
T_{\text {base3,Diode }}=125^{\circ} \mathrm{C}\end{array}$ \\
\hline $\begin{array}{l}\text { Correction coefficient of switching loss for junction } \\
\text { temperature relative to the base junction temperature }\end{array}$ & $K_{\mathrm{sw}, \mathrm{IGBT}}=0.199$ & $K_{\text {sw }, \text { Diode }}=0.443$ \\
\hline $\begin{array}{l}\text { Conduction saturation voltage at base junction } \\
\text { temperature with base blocking voltage }\end{array}$ & $U_{\text {sat }, \mathrm{IGBT}}=1.81172 \mathrm{~V}$ & $U_{\text {sat,Diode }}=1.61061 \mathrm{~V}$ \\
\hline $\begin{array}{l}\text { Conduction resistance at base junction temperature } \\
\text { with base blocking voltage }\end{array}$ & $R_{\mathrm{IGBT}}=0.00794 \Omega$ & $R_{\text {Diode }}=0.00595 \Omega$ \\
\hline $\begin{array}{l}\text { Correction coefficient of conduction saturation voltage } \\
\text { for junction temperature relative to the base junction } \\
\text { temperature }\end{array}$ & $K_{u_{\mathrm{sat}, \mathrm{GBT}}}=0.0013104$ & $K_{u_{\text {sat, Diode }}}=-0.002066$ \\
\hline $\begin{array}{l}\text { Correction coefficient of conduction resistance for } \\
\text { junction temperature relative to the base junction } \\
\text { temperature }\end{array}$ & $K_{r_{\text {sal.IGBT }}}=0.0000385$ & $K_{r_{\text {sat, Diode }}}=0.0000103$ \\
\hline \multirow{4}{*}{ Thermal resistances } & $R_{1, \mathrm{IGBT}}=0.02565 \mathrm{~K} / \mathrm{W}$ & $R_{1, \text { Diode }}=0.04860 \mathrm{~K} / \mathrm{W}$ \\
\hline & $R_{2, \mathrm{IGBT}}=0.01425 \mathrm{~K} / \mathrm{W}$ & $R_{2, \text { Diode }}=0.02700 \mathrm{~K} / \mathrm{W}$ \\
\hline & $R_{3, \mathrm{IGBT}}=0.00342 \mathrm{~K} / \mathrm{W}$ & $R_{3, \text { Diode }}=0.00648 \mathrm{~K} / \mathrm{W}$ \\
\hline & $R_{4, \mathrm{IGBT}}=0.01368 \mathrm{~K} / \mathrm{W}$ & $R_{4, \text { Diode }}=0.02592 \mathrm{~K} / \mathrm{W}$ \\
\hline \multirow{4}{*}{ Thermal capacitors } & $C_{1, \mathrm{IGBT}}=1.16959 \mathrm{~J} / \mathrm{K}$ & $C_{1, \text { Diode }}=0.61728 \mathrm{~J} / \mathrm{K}$ \\
\hline & $C_{2, \mathrm{IGBT}}=7.01754 \mathrm{~J} / \mathrm{K}$ & $C_{2, \text { Diode }}=3.70370 \mathrm{~J} / \mathrm{K}$ \\
\hline & $C_{3, \mathrm{IGBT}}=87.7193 \mathrm{~J} / \mathrm{K}$ & $C_{3, \text { Diode }}=46.2963 \mathrm{~J} / \mathrm{K}$ \\
\hline & $C_{4, \mathrm{IGBT}}=73.0994 \mathrm{~J} / \mathrm{K}$ & $C_{4, \text { Diode }}=38.5802 \mathrm{~J} / \mathrm{K}$ \\
\hline
\end{tabular}

The results of proposed loss calculation method, formula calculation and the commercial software were as shown in Table 4. The differences are small mainly due to the curve fitting. And the switching loss calculation of device current in commercial software is based on lineation fitting rather than exponential fitting. 
Table 4. Results of the Three Methods

\begin{tabular}{cccccccccc}
\hline & \multicolumn{3}{c}{ Proposed method } & \multicolumn{3}{c}{ Formula calculation } & \multicolumn{3}{c}{ Commercial software } \\
\hline Frequency $(\mathrm{Hz})$ & 1000 & 2000 & 5000 & 1000 & 2000 & 5000 & 1000 & 2000 & 5000 \\
$P_{\text {sw,IGBT }}(\mathrm{W})$ & 156.8 & 548.1 & 1304.0 & 259.7 & 562.5 & 1614.0 & 279.1 & 558.2 & 1395.5 \\
$P_{\text {con,IGBT }}(\mathrm{W})$ & 381.5 & 380.4 & 384.0 & 298.6 & 321.7 & 390.8 & 340.3 & 340.3 & 340.3 \\
$P_{\text {sw,Diode }}(\mathrm{W})$ & 128.3 & 214.3 & 555.8 & 89.4 & 211.9 & 710.3 & 96.3 & 192.6 & 481.5 \\
$P_{\text {con,Diode }}(\mathrm{W})$ & 46.3 & 46.2 & 46.0 & 46.0 & 45.9 & 45.8 & 45.9 & 45.9 & 45.9 \\
$P_{\text {total }}(\mathrm{W})$ & 712.9 & 1189.0 & 2289.8 & 693.7 & 1142.0 & 2409.9 & 775.7 & 1151.1 & 2277.3 \\
$P_{\text {total,err }} \%$ & 0 & 0 & 0 & -2.7 & -4.0 & 5.2 & 8.8 & -3.2 & -0.5 \\
\hline
\end{tabular}

\section{Experimental Verification of the Loss Calculation Method}

In order to verify the loss calculation method proposed in this paper, a $400 \mathrm{~kW}$ converter experimental platform was built with direct torque control strategy for induction motor driving. Model FF200R33KF2C of Infineon was used.

The switching frequency in direct torque control strategy is influenced by motor parameters, hysteresis band width and other factors. It is difficult to get the realtime inter-coupling parameters through theoretical analysis. According to the scope of parameters obtained by experiment or simulation, the fluctuation range of power loss can be given through the simulation calculation. The steady state operating point of power loss and junction temperature within the device would be provided by the iterative calculation so that the distribution resistance for thermal management is tested to be appropriate or not.

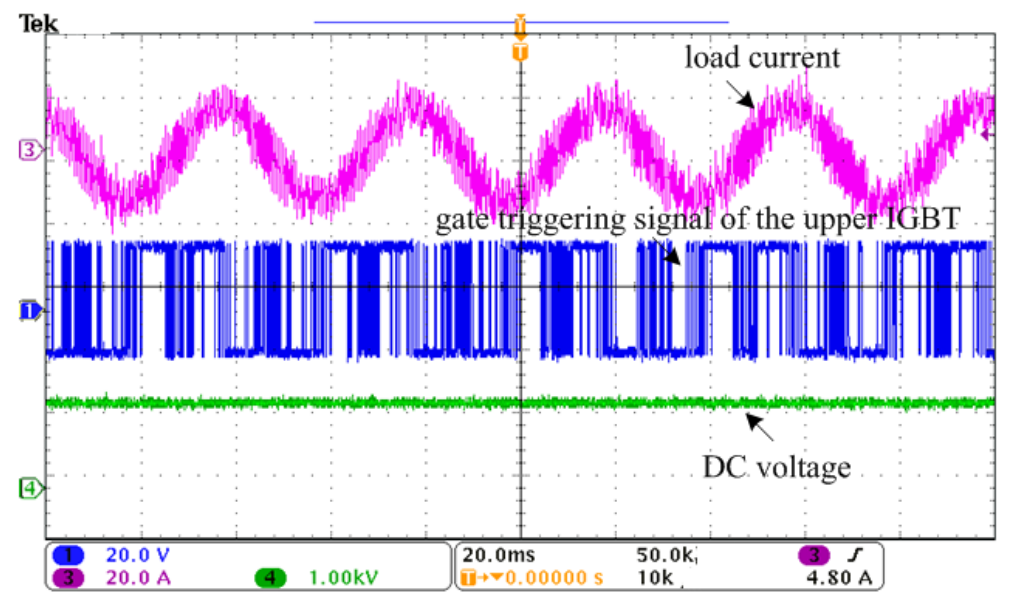

Figure 4 Sample Measurements in Phase Arm U

Sample measurements are shown in Figure 4. The upper waveform represents the load current in phase arm $\mathrm{U}$, the middle waveform represents the gate triggering signal of lower IGBT and the lower waveform shows DC voltage. As the average power loss of the device would be obtained by the energy loss divided by the cycle time. Measurements were recorded and the gate triggering signal was saved as 0 when the voltage is lower than the threshold voltage of IGBT and 1 when the gate voltage is higher than the threshold voltage.

It is shown that the results of proposed loss calculation method match those from hardware measurements in Table 5. 
Table 5. Results of Proposed Method and Experiment

\begin{tabular}{cccccccc}
\hline \multicolumn{4}{c}{ Proposed method } & \multicolumn{5}{c}{ Experiment } \\
\hline Average & $P_{\text {sw,avg }}$ & $P_{\text {con,avg }}$ & $P_{\text {total,avg }}$ & Average & $P_{\text {sw,avg }}$ & $P_{\text {con,avg }}$ & $P_{\text {total,avg }}$ \\
Frequency $(\mathrm{Hz})$ & $(\mathrm{W})$ & $(\mathrm{W})$ & $(\mathrm{W})$ & Frequency(Hz) & $(\mathrm{W})$ & $(\mathrm{W})$ & $(\mathrm{W})$ \\
1013 & 61.1 & 4.8 & 65.9 & 980 & 55.8 & 7.87 & 63.67 \\
\hline
\end{tabular}

Inaccuracies in individual IGBT and diode power loss are mainly due to the inaccurate data extraction from datasheet, and the differences between simulation and actual systems, such as switching frequency, the current though device while switching, and so on.

\section{Summary}

A simulation method of calculating power loss of IGBT-diode under non-ideal conditions was presented. The mathematical model of power loss calculation was established with quadratic polynomial fitting data according to the theory of the least-square method and working states of devices which could be determined by load current and gate triggering signals considering dead time. With this method, the scope of parameters would be given directly by experiment or simulation and need not being idealized. The simulation results present the features of actual working state parameters to some extent. Especially for some complex control strategies and topologies, some parameters required are difficult to be obtained through theoretical derivation or experiments. Certain scope and reference values of these parameters can be provided by simulation at least. The influence of parameters on the results of power loss calculation can be investigated by changing the parameter values to provide useful guidance for converter design. By comparing the results of proposed loss calculation method with those of formula calculation and commercial software at fixed switching frequency with ideal sinusoidal periodic bipolar SPWM modulation, the validity and reliability of this method were verified. Through design of two-level converter in hysteretic control, experimental verification of the loss calculation method calculating power losses of IGBTs and anti-parallel diodes were applied. It was proved that the results would be accurate. The simulation method is expected to be easily extended to other converter topologies and control strategies.

\section{References}

[1] A. Choudhury, P. Pillay, M. Amar and S.S. Williamson, "Performance comparison study of two and three-level inverter for electric vehicle application," in Transportation Electrification Conference and Expo (ITEC), (2014) pp. 1-6.

[2] M. Schweizer and J.W. Kolar, "Design and Implementation of a Highly Efficient Three-Level T-Type Converter for Low-Voltage Applications," IEEE Transactions on Power Electronics, vol. 28, no. 2, (2013), pp. 899-907.

[3] S. Bernet, "Recent developments of high power converters for industry and traction applications," Power Electronics, IEEE Transactions on, vol. 15, no. 6, (2000), pp. 1102-1117.

[4] S. Dieckerhoff, S. Bernet and D. Krug, "Power Loss-Oriented Evaluation of High Voltage IGBTs and Multilevel Converters in Transformerless Traction Applications," IEEE Transactions on Power Electronics, vol. 20, no. 6, (2005), pp. 1328-1336.

[5] B. Alamri and M. Darwish, "Precise modelling of switching and conduction losses in cascaded h-bridge multilevel inverters," Power Engineering Conference (UPEC), 2014 49th International Universities, (2014) pp. 1-6.

[6] P. The-Minh, G. Riedel, N. Oikonomou and M. Pacas, "PWM for active thermal protection in three level neutral point clamped inverters," ECCE Asia Downunder (ECCE Asia), 2013 IEEE, (2013), pp. 906-911.

[7] A.V. Rocha, Sidelmo M. Silva, Igor A. Pires, Alysson A. P. Machado, F. V. Amaral, V. N. Ferreira, H. de Paula and B. J. Cardoso Filho, "A new fault-tolerant realization of the active three-level NPC converter;" Energy Conversion Congress and Exposition (ECCE), 2014 IEEE, (2014) pp. 3483-3490.

[8] B. Kaku, I. Miyashita and S. Sone, "Switching loss minimised space vector PWM method for IGBT 
three-level inverter," Electric Power Applications, IEE Proceedings, vol. 144, no. 3, (1997), pp. 182-190

[9] A.M. Bazzi, P.T. Krein, J.W. Kimball and K. Kepley, "IGBT and Diode Loss Calculation Under Hysteresis Switching." IEEE Transactions on Power Electronics, vol. 27, no. 3, (2012), pp. 1044-1048.

[10] D. Xu, H. Lu, L. Huang, S. Azuma, M. Kimata and R. Uchida, "Power loss and junction temperature analysis of power semiconductor devices," Industry Applications, IEEE Transactions on, vol. 38, no. 5, (2002), pp. 1426-1431.

[11] A.T. Bryant, L. Lu, E. Santi, J. L. Hudgins and P. R. Palmer, "Modeling of IGBT Resistive and Inductive Turn-On Behavior," IEEE Transactions on Industry Applications, vol. 44, no. 3, (2008), pp. 904-914.

[12] A. Ramamurthy, S. Sawant and B. J. Baliga, "Modeling the [dV/dt] of the IGBT during inductive turn off," Power Electronics, IEEE Transactions on, vol. 14, no. 4, (1999), pp. 601-606.

[13] S.C. Das, G. Narayanan and A. Tiwari, "Experimental study on switching characteristics of an inverter leg consisting of IGBTs of dissimilar makes," Electrical Energy Systems (ICEES), 2014 IEEE 2nd International Conference on, (2014), pp. 235-240.

[14] O.S. Senturk, L. Helle, S. Munk-Nielsen, P. Rodriguez and R. Teodorescu, "Converter Structure-Based Power Loss and Static Thermal Modeling of The Press-Pack IGBT Three-Level ANPC VSC Applied to Multi-MW Wind Turbines," IEEE Transactions on Industry Applications, vol. 47, no. 6, (2011), pp. $2505-2515$.

[15] K. Ma, A.S. Bahman, S.M. Beczkowski and F. Blaabjerg, "Loss and thermal model for power semiconductors including device rating information," Power Electronics Conference (IPEC-Hiroshima 2014 - ECCE-ASIA), 2014 International, (2014) pp. 2862-2869.

[16] A.T. Bryant, X. Kang, E. Santi, P. R. Palmer and J. L. Hudgins, "Two-step parameter extraction procedure with formal optimization for physics-based circuit simulator IGBT and p-i-n diode models;" Power Electronics, IEEE Transactions on, vol. 21, no. 2, (2006), pp. 295-309.

[17] C.M.C.A. D. Barlini, "New technique for the measurement of the static and of the transient junction temperature in IGBT devices under operating conditions," Microelectronics Reliability, vol. 46, (2006), pp. 1772-1777.

[18] Y. Luo, Y. Kajita, T. Hatakeyama, S. Nakagawa and M. Ishizuka, "Thermal transient test based thermal structure function analysis of IGBT package," Electronics Packaging (ICEP), 2014 International Conference on, (2014) pp. 596-599.

[19] FF200R33KF2C DATASHEET, http://www.infineon.com, October 3rd, (2013).

[20] Dimensioning program IPOSIM for loss and thermal calculation of Infineon IGBT modules, http://www.infineon.com. 